\title{
Prophylactic Use of Tranexamic Acid in Reducing Blood Loss during Elective Cesarean Section
}

\author{
Ayman A. Soliman, Sayed A. Mahmoud, Ragab M. Dawood, Aliaa A. Fayed, Amira A. Fathey \\ Department of Obstetrics and Gynecology, Faculty of Medicine, Menoufia University, Menoufia, Egypt \\ Corresponding Author: Aliaa Ali Mohamed Fayed, Mobile: (+20)01008106648, E-Mail: aliaafayed3@ gmail.com
}

\begin{abstract}
Background: Primary postpartum hemorrhage (PPH) plays a major role in maternal mortality and morbidity like severe anemia, blood transfusion requirement, hospital stay and infection. Tranexamic acid is now recommended in treatment of PPH, yet its prophylactic use before delivery is still not recommended.

Objective: To assess the efficacy of preoperative administration of Tranexamic acid in decreasing blood loss during elective cesarean section.

Patients and Methods: The study was conducted at Department of Obstetrics and Gynecology of Menoufia University Hospitals. It included 100 pregnant females who went through elective cesarean section with age $>18$ and $<35$ years and singleton alive fetus. They were randomly allocated to two groups: the study group of which women received $1 \mathrm{gm}$ of tranexamic acid 20 minutes before skin incision and the control group who did not receive tranexamic acid. The assessment included the following: measurement of blood loss amount and estimation of postoperative 1st day hemoglobin and hematocrit value.

Results: There was highly statistically significant difference between both groups regarding the amount of blood loss during cesarean delivery and blood loss 2 hours from end of CS $(\mathrm{p} \leq 0.001)$. This was reflected in the percentage of difference of preoperative and postoperative hemoglobin and hematocrit values, which showed highly significant statistical difference $(\mathrm{p} \leq 0.001)$.

Conclusion: Tranexamic acid administration before elective cesarean section was effective in decreasing intraoperative and postoperative bleeding. And in turn reduces the incidence of PPH with no immediate maternal or neonatal side effects.
\end{abstract}

Keywords: Cesarean section, Postpartum hemorrhage, Tranexamic acid.

\section{INTRODUCTION}

Cesarean section (CS) is considered one of the most common surgeries in the entire world ${ }^{(1)}$. In the last three decades, increased cesarean delivery rates has been a worldwide concern, witnessed in both developing and developed conutries. In Egypt, women with less than 3 living children were twice more likely to go through caesarean birth than women with more parity ${ }^{(2)}$. Primary postpartum hemorrhage (PPH) plays a major role in maternal mortality and morbidity like severe anemia, blood transfusion requirement, hospital stay and infection ${ }^{(3)}$, with about 295000 women died during childbearing and follwing parturition. About $94 \%$ of these deaths took place in settings with poor resources, with about $65 \%$ (two thirds) occurred in the World Health Organization (WHO) African region ${ }^{(4)}$.

In 2017, WHO recommended that tranexamic acid (TXA) should be given in the first 3 hours following delivery in-patient with established diagnosis of PPH, alongside basic established care for all patients either with PPH delivered vaginally or by cesarean section ${ }^{(5)}$. For this reason, we designed this prospective randomized control trial to analyze effect of prophylactic administration of TXA in decreasing bleeding during caesarean section.

\section{PATIENTS AND METHODS}

This prospective randomized clinical study was carried out in Department of Obstetrics and
Gynecology, Menoufia University Hospital in the period from March 2019 to March 2020. The study included 100 pregnant women who underwent elective cesarean section.

After excluding patients who did not meet inclusion criteria and those who declined to participate, the patients were randomized into two groups. Group (A) (study group): pregnant women who received $1 \mathrm{gm}$ of tranexamic acid 20 minutes before skin incision and Group (B) (control group): pregnant women who did not receive tranexamic acid. Sealed, consecutively numbered envelopes containing computer-generated number (Randomization Generator Version 1.0) were opened when the women were recruited. The allocation ratio was 1:1. The Patients were blinded to the groups.

A full general examination, including blood pressure (BP), pulse, height, and weight, was done first. Then, body mass index (BMI) was calculated and recorded. Ultrasound was done to ensure viability and to determine the gestational age, the presenting part, the position of the placenta and the amniotic fluid. Preoperative routine investigation $\mathrm{CBC}, \mathrm{PT}, \mathrm{ABO} \&$ $\mathrm{Rh}$ typing was done.

Preoperative administration of $1 \mathrm{gm}$ of tranexamic acid [AMOUN company, as $5 \mathrm{~mL}$ ampoule containing $500 \mathrm{mg}$ ( $100 \mathrm{mg} / \mathrm{mL}$ solution) that is, $1 \mathrm{~g} / 10$ $\mathrm{mL}$ ] intravenously over $10 \mathrm{~min}$ at a rate of $1 \mathrm{~mL} / \mathrm{min}$, about $20 \mathrm{~min}$ before skin incision in the study group with no drug is given to control group. 1 gram of TXA

This article is an open access article distributed under the terms and conditions of the Creative Commons Attribution (CC BY-SA) license (http://creativecommons.org/licenses/by/4.0/) 
was chosen for this study, as per Updated WHO Recommendation on Tranexamic Acid for the Treatment of Postpartum Hemorrhage ${ }^{(5)}$. All CS were done under spinal anesthesia and all the surgeries were performed by assistant lecturer or higher stuff. In both groups 20 units of oxytocin (Syntocinon, Novartis CO., Egypt) in $500 \mathrm{~mL}$ of normal saline was infused intravenously over 20 to 30 minutes after delivery of fetus. Additional 20 units of oxytocin was given postoperatively (10 $\mathrm{U}$ in each bottle of IV fluid for two consecutive bottles over a period of 12 hours).

Assessment of blood loss intraoperative and 2 hours postoperative using gravimetric measurement. It constitutes placing an absorbable sheet under the patients. Weighting of these absorbable sheets after cesarean section as well as materials such as soaked pads and gauzes on a sensitive scale and subtracting the known dry weights of these materials to determine the achieved weight, which represent the actual blood loss (6).

-The achieved weight $=$ (weight of absorbable sheets, soaked pads, soaked gauzes) - (dry weights of these materials). Volume of blood loss $(\mathrm{ml})=$ the achieved weight $(\mathrm{gm}) \div 1.06$

Postoperative $\mathrm{Hb}$ and HCT estimation was done within $24 \mathrm{~h}$ after the surgery (after discontinuation of IV fluids) for all the women and compared to the preoperative value. All cases were monitored for 2 hours postoperatively.

Vitals (heart rate, blood pressure, oxygen saturation, urine output, uterine contractility status, and side effects if any was noted at regular intervals. Apart from routine postoperative care, all women were observed for any increased bleeding per vagina and additional pre weighed pads were provided along with measures to reduce bleeding if needed.

Ethical and patients' approval: The study was approved from the Ethical Committee, Faculty of Medicine, Menoufia University and written informed consent was obtained from all cases.

\section{Statistical analysis}

Results were collected, tabulated and statistically analyzed by an IBM compatible personal computer with SPSS statistical package version 23. The used tests of significance included: Student t-test, Paired ttest and Preason correlation. $\mathrm{P}$ value at 0.05 was used to determine significance where P-value $\leq 0.05$ is statistically significant.

\section{RESULTS}

There was no statistically significant difference between the both groups regarding demographic data including age, gravidity, gestational age in weeks and parity $(\mathrm{p}>0.05)$ (Table 1$)$.

This study showed highly statistically significant difference in blood loss during cesarean delivery and blood loss 2 hours after end of CS between study group and control group ( $\mathrm{p}<0.001)$. The total amount of blood loss ranged between $(318-556 \mathrm{ml})$ in study group compared to control group, which ranged between (463-769 ml) which is highly statistically significant ( $\mathrm{p}$ $\leq 0.001)$ (Table 2).

None of both study \& control group women had PPH (blood loss $>1000 \mathrm{ml}$ ) and about $22 \%$ only of study group had blood loss $>500 \mathrm{ml}$ and about $86 \%$ of control group had blood loss $>500 \mathrm{ml}$. Additionally, a highly significant statistical difference $(\mathrm{p} \leq 0.001)$ was shown between the two groups in the secondary outcomes.

Percentage of difference in hemoglobin and hematocrit values pre \& postoperative; with a mean preoperative $\mathrm{Hb}$ level $10.36 \mathrm{gm} / \mathrm{dl}$ in study group and $10.26 \mathrm{gm} / \mathrm{dl}$ in control group before onset of CS (Table 3). There was no blood transfusion required in either of the groups postoperatively nor additional surgical interventions in both groups.

There were no adverse effects, admission to ICU or immediate postpartum and neonatal complications. All patients were discharged alive.

Table (1): Comparison of age, parity, GA and anthropometric measurement of studied groups $\mathrm{No}=100$

\begin{tabular}{||l|c|c|c|c|}
\hline Mean \pm standard deviation & $\begin{array}{c}\text { Group A } \\
\text { No=50 }\end{array}$ & $\begin{array}{c}\text { Group B } \\
\text { No=50 }\end{array}$ & t-test & P value \\
\hline Age (years) & $21.46 \pm 2.71$ & $21.46 \pm 2.71$ & 0.282 & 0.778 \\
Median & 21.50 & 21.50 & & Ns \\
\hline Gestational age ( weeks) & $39.34 \pm 0.47$ & $39.28 \pm 0.45$ & 0.643 & 0.521 \\
Median & 39 & 39 & & NS \\
\hline Parity & $0.66 \pm 0.47$ & $0.72 \pm 0.45$ & 0.643 & 0.521 \\
Median & 1 & 1 & & NS \\
\hline Weight (kg) & $73.88 \pm 6.32$ & $71.96 \pm 6.72$ & 1.47 & 0.145 \\
Median & 76 & 70 & & NS \\
\hline Height $(\mathbf{c m})$ & $159.7 \pm 4.09$ & $159.8 \pm 4.65$ & 0.137 & 0.891 \\
Median & 159.50 & 159 & & NS \\
\hline BMI $\left(\mathbf{k g} / \mathbf{m}^{2}\right)$ & $29.01 \pm 2.23$ & $28.22 \pm 2.06$ & 1.84 & 0.069 \\
Median & 29.35 & 27.50 & & NS \\
\hline
\end{tabular}

Group $\mathrm{A}=$ study group Group $\mathrm{B}=$ control group $\mathrm{NS}=$ =non-significant $\mathrm{S}=$ significant 
Table (2): Comparison of blood loss between studied groups no $=100$

\begin{tabular}{|l|c|c|c|c||}
\hline Mean \pm standard deviation & $\begin{array}{c}\text { Group A } \\
\text { No=50 }\end{array}$ & $\begin{array}{c}\text { Group B } \\
\text { No=50 }\end{array}$ & t-test & P value \\
\hline $\begin{array}{l}\text { Blood loss during cesarean } \\
\text { delivery (ml) }\end{array}$ & $\begin{array}{c}286.82 \pm 47.42 \\
\text { Median }\end{array}$ & $\begin{array}{c}406.74 \pm 60.56 \\
403\end{array}$ & 11 & $<0.001$ \\
\hline $\begin{array}{l}\text { Blood loss from end of C.S to 2 } \\
\text { hours after (ml) }\end{array}$ & $\begin{array}{c}143.46 \pm 23.61 \\
\text { Median }\end{array}$ & $\begin{array}{c}203.36 \pm 30.30 \\
201\end{array}$ & 11.02 & $\begin{array}{c}<0.001 \\
\text { HS }\end{array}$ \\
\hline $\begin{array}{l}\text { Total amount of blood loss (ml) } \\
\text { Median }\end{array}$ & $\begin{array}{c}430.28 \pm 71.03 \\
424\end{array}$ & $\begin{array}{c}610.10 \pm 90.87 \\
604\end{array}$ & 11.02 & $\begin{array}{c}<0.001 \\
\text { HS }\end{array}$ \\
\hline
\end{tabular}

Group $\mathrm{A}=$ study group Group $\mathrm{B}=$ control group $\mathrm{HS}=$ High-significant

Table (3): comparison of $\mathrm{Hb}$ and $\mathrm{HCT}$ between studied groups no $=100$

\begin{tabular}{|l|c|c|c|c|}
\hline Mean \pm standard deviation & Group A No=50 & $\begin{array}{c}\text { Group B } \\
\text { No=50 }\end{array}$ & t test & P value \\
\hline Hb Pre- operative & $10.36 \pm 0.66$ & $10.26 \pm 0.76$ & & 0.525 \\
Median & 10.40 & 10.35 & 0.638 & NS \\
\hline Hb post- operative & $9.79 \pm 0.67$ & $9.22 \pm 0.76$ & 3.95 & $<0.001$ \\
Median & 9.80 & 9.35 & & HS \\
\hline HCT pre -operative & $31.06 \pm 2.006$ & $30.79 \pm 2.30$ & 0.620 & 0.537 \\
Median & 31 & 31 & & \\
\hline HCT post -operative & $29.37 \pm 2.056$ & $27.63 \pm 2.29$ & 3.98 & $<0.001$ \\
Median & 29.40 & 28 & & HS \\
\hline
\end{tabular}

HS=High-significant

\section{DISCUSSION}

TXA is known for a long time as

an antifibrinolytic agent discovered by Utako Okomoto in $1950 \mathrm{~s}^{(7)}$, but its prophylactic use in prevention of postpartum hemorrhage through reduction of blood loss during \& after cesarean section or vaginal birth is quite new.

It is known that during placental delivery there is release of coagulant factors along with hyperfibrinolysis and fibrinogen depletion owing to vascular injury and these physiological events can last for several hours postpartum ${ }^{(8)}$. During CS, there is extensive tissue injury during the procedure, which leads to further increase in fibrinolysis and resultant bleeding ${ }^{(9)}$. Therefore, TXA can effectively control the bleeding by arresting fibrinolysis.

This study was a randomized, prospective, interventional control study, which compared the efficacy of TXA administration preoperatively in decreasing blood loss during elective C.S between study and control groups. Blood loss was estimated intraoperatively using gravimetric method. Postoperatively, vital parameters were recorded and patients were monitored for any side effects. TXA reaches its highest plasma concentration within 1 hour after intravenous administration and its therapeutic levels can be maintained for approximately 8 hours after operation, which covers the period of hyperfibrinolysis. This explain the efficacy of TXA in decreasing mean blood loss significantly intraoperative and up to 2 hours postpartum as shown in this study alongside other previous studies. A meta-analysis included around 40138 bleeding patients (traumatic and post-partum hemorrhage), concluded that early administration of TXA improved survival by more than $70 \%$ and $10 \%$ decrease in survival rate occur with every 15 min delay in treatment administration during the first 3 hours with no benefit gained after 3 hours ${ }^{(\mathbf{1 0})}$.

In our study, we used TXA at a fixed dose of 1 gm in $10 \mathrm{~mL}(100 \mathrm{mg} / \mathrm{mL}) \mathrm{IV}$ at $1 \mathrm{~mL}$ per minute, thereby taking $10 \mathrm{~min}$ for the drug administration (as per recent WHO recommendation of use of tranexamic acid for the treatment of postpartum hemorrhage) ${ }^{(5)}$. This was done about $20 \mathrm{~min}$ before skin incision, as the onset of action of TXA is 5-15 mins. TXA should not be administrated through a line with blood, or mixed with solutions containing penicillin. ${ }^{(11)}$.

In present study, the mean blood load was significantly less in study group compared to control group for intraoperative bleeding $(286.82 \pm 47.42 \mathrm{ml}$ Vs $406.74 \pm 60.56 \mathrm{ml}$ ) as well as postoperative bleeding (from end of CS to 2 hours postpartum) $(143.46 \pm 23.61 \mathrm{ml}$ Vs $203.36 \pm 30.30 \mathrm{ml} ; \mathrm{p}<0.001)$ respectively. This difference in mean blood loss in each group was reflected in the difference of mean $\mathrm{HB} \%$ and HCT value after surgery in the two groups which was high statistically significant.

Movafegh et al. ${ }^{(12)}$ used TXA in dose of 10 $\mathrm{mg} / \mathrm{kg}$, given $20 \mathrm{~min}$ before skin incision at caesarean delivery. Mean blood loss was significantly less in the 
study group compared with the control group for both intraoperative bleeding (262.5 \pm 39.6 vs. $404.7 \pm 94.4$ $\mathrm{ml})$ and postoperative bleeding $(67.1 \pm 6.5$ vs. $141.0 \pm$ $33.9 \mathrm{ml} ; \mathrm{p}<0.001)$, respectively. These results are consistent with our study. A study by Abdel Aleem et al. ${ }^{(13)}$ included the blood loss from the beginning of CS until two hours postpartum inclusive of amniotic fluid and showed significant reduction in mean blood loss during and for 2 hours postoperatively after randomization of 740 subjects, which is similar to our results. One trial used 2 different doses of TXA by forming three groups ( 2 study groups and one control group) one Group received $10 \mathrm{mg} / \mathrm{kg}$ of TXA in $20 \mathrm{ml}$ of $5 \%$ dextrose, given intravenously, while the second group received $15 \mathrm{mg} / \mathrm{kg}$ and the third group (control group) was given a placebo. There was no significant difference in postoperative blood loss in all three groups. Pre- and post-operative hemoglobin levels differed significantly when compared to control group (14). Another randomized, double blinded, casecontrolled study by $\mathbf{X u}$ et al. ${ }^{(15)}$ was conducted on around 174 primipara underwent C.S, during which study group ( 88 women) was given $10 \mathrm{mg} / \mathrm{kg}$ of TXA just before C.S. There was significant less blood loss in the period between the end of CS and $2 \mathrm{~h}$ postpartum in the study group than the control group $(\mathrm{p}<0.01)$, with no significant decrease in blood loss from placental delivery to the end of C.S $(p=0.17)$. Two hundred and twenty-three (223) women who underwent elective C.S were included in Yehia et al., ${ }^{(16)}$ study during which $1 \mathrm{gm}$ of TXA was given over 2 minutes to study group along with induction of anesthesia. TXA significantly reduced the amount of blood loss during CS with decreasing postpartum requirements of iron replacement ${ }^{(16)}$. A study by Sahu et $\boldsymbol{a l} .{ }^{(17)}$ showed that there was significantly lesser total blood loss (intraoperative as well as postoperative) in study group versus control group $(\mathrm{P}<0.05)$, with only three women $(6 \%)$ had PPH in control group. No side effects were noted in women or neonates. Novikova $\boldsymbol{e t}$ $\boldsymbol{a l}^{(\mathbf{1 8 )}}$, conducted a systematic review of twelve trials involving 3285 women undergoing elective C.S (nine trials, 2453 participants) or spontaneous vaginal birth (three trials, 832 participants) and found that TXA use in addition to uterotonic medications was effective in decreasing blood loss greater than $1000 \mathrm{ml}$ in C.S but not vaginal birth. Blood loss greater than $400 \mathrm{ml}$ or 500 $\mathrm{ml}$ was more apparent in women having vaginal birth than in women undergone C.S. It also prevents occurrence of PPH postpartum and blood transfusion in women at low risk of PPH following both C.S and vaginal delivery.

The limitation of our study is that the long-term side effect of TXA use were not taken into account. A large upcoming multicenter randomized, double-blind, placebo- controlled trial included 4524 women with cesarean deliveries and seeked to determine if the benefits of the routine prophylactic use of tranexamic acid after cesarean delivery significantly overcome its potential side effects in the 3 months after delivery ${ }^{(\mathbf{1 9})}$.

The poor nutritional and antenatal care status of most pregnant women attending our hospital is reflected in the demographic data of this study with mean preoperative hemoglobin levels of $10.36 \mathrm{~g} / \mathrm{dl}$. In most cases of $\mathrm{PPH}$, there is no identifiable risk factor with most women have low risk pregnancies. Therefore, prevention of postpartum hemorrhage and possible postpartum blood loss is essential besides improving antenatal care and treating anemia as this may reduce the morbidity associated with $\mathrm{PPH}$.

TXA is an antifibrinolytic agent which is widely available, cheap, safe and easy to store (unlike oxytocin), which does not need maintenance of cold chain. However, long-term side effect of the drug on the mother and her baby was difficult in our settings due to poor follow up.

\section{CONCLUSION}

Prophylactic administration of tranexamic acid, an antifibrinolytic agent, prior to cesarean section was effective in reducing intraoperative, postoperative blood loss and subsequently reduces the incidence of postpartum hemorrhage as well as reduces blood transfusion requirement and its related complication without any immediate maternal or neonatal adverse events.

\section{REFERENCES}

1. Betrán A, Ye J, Moller A et al. (2016): The increasing trend in caesarean section rates: global, regional and national estimates: 1990-2014. PloS One, 11 (2): e0148343.

2. Yassin K, Saida G (2012): Levels and determinants of caesarean deliveries in Egypt: pathways to rationalization. Internet $\mathrm{J}$ World Health Societal Politics, 7 (2): 16-22.

3. Henry D, Carless P, Moxey A et al. (2011): Antifibrinolytic use for minimizing perioperative allogeneic blood transfusion. The Cochrane Library, 19 (1): 188693.

4. World Health Organization (2019): Trends in maternal mortality 2000 to 2017: estimates by WHO, UNICEF, UNFPA, World Bank Group and the United Nations Population Division: executive summary. World Health Organization. https://apps.who.int/iris/handle/10665/327596. License: CC BY-NC-SA 3.0 IGO

5. World Health Organization (2017): WHO recommendation on tranexamic acid for the treatment of postpartum haemorrhage. Geneva: World Health Organization. Licence: CC BY-NC-SA 3.0 IGO. https://apps.who.int/iris/ bitstream/handle/ 10665/ 259374/ 9789241550154-eng.pdf?sequence=1

6. Al Kadri H, Al Anazi B, Tamim H (2011): Visual estimation versus gravimetric measurement of postpartum blood loss: a prospective cohort study. 
Archives of Gynecology and Obstetrics, 283 (6): 120713.

7. Okamoto S, Sato S, Takada Y et al. (1964): An Active Stereo-Isomer (Trans-Form) of Amcha and Its Antifibrinolytic (Antiplasminic) Action in Vitro and in Vivo. Keio J Med., 13: 177-85.

8. Dhivya Lakshmi S, Abrahim R (2016): Role of prophylactic traenexamic acid in reducing blood loss during elective caesarean section: A randomized controlled study. J Clin Diagn Res., 10: 17-21.

9. Levy J, Dutton R, Hemphill J et al. (2010): Hemostasis summit participants: Multidisciplinary approach to the challenge of hemostasis. Anesth Analg., 110: 354-364.

10. Gayet-Ageron A, Prieto-Merino $\mathrm{D}$, Ker $\mathrm{K}$ et al. (2018): Effect of treatment delay on the effectiveness and safety of antifibrinolytics in acute severe haemorrhage: a meta-analysis of individual patient-level data from 40-138 bleeding patients. Lancet, 391: 125.

11. Malathi P, Anupama $D$, Habitha $P$ (2016): Effect of injection Tranexamic acid on perioperative blood loss during caesarean section. IAIM., 3 (10): 280-289.

12. Movafegh A, Eslamian L, Dorabadi A (2011): Effect of intravenous tranexamic acid administration on blood loss during and after caesarean delivery. Int J Gynaecol Obstet., 115: 224-226.

13. Abdel-Aleem H, Alhusaini T, Abdel-Aleem $M$ et al. (2013): Effectiveness of tranexamic acid on blood loss in patients undergoing elective cesarean section: Randomized clinical trial. J Matern Fetal Neonatal Med., 26: 1705-1709
14. Goswami U, Sarangi S, Gupta S et al. (2013): Comparative evaluation of two doses of tranexamic acid used prophylactically in anaemic parturients for lower segment cesarean section: A double-blind randomized case control prospective trial. Saudi Journal of Anaesthesia, 7 (4): 427-432.

15. Xu J, Gao W, Ju Y (2013): Tranexamic acid for the prevention of postpartum hemorrhage after cesarean section: a double-blind randomization trial. Arch Gynecol Obstet., 287 (3): 463-468.

16. Yehia A, Koleib M, Abdelazim I et al. (2014): Tranexamic acid reduces blood loss during and after cesarean section: A double blinded, randomized, controlled trial. Asian Pacific Journal of Reproduction, 3 (1): 53-56.

17. Sahu J, Mishra N (2019): Role of intravenous tranexamic acid in reducing blood loss during caesarean section: Study at tribal-dominated area hospital in Chhattisgarh, India. J Obstet Gynaecol Res., 45: 841848.

18. Novikova N, Hofmeyr G, Cluver C (2015): Tranexamic acid for preventing postpartum haemorrhage. https://pubmed.ncbi.nlm.nih.gov/26079202/

19. Sentilhes L, Daniel V, Deneux-Tharaux C (2020): TRAAP2 Study Group and the Groupe de Recherche en Obstétrique et Gynécologie (GROG). TRAAP2 TRAnexamic Acid for Preventing postpartum hemorrhage after cesarean delivery: a multicenter randomized, doubleblind, placebo- controlled trial - a study protocol. BMC Pregnancy Childbirth, 20 (1): 6369. 